\title{
Study Time after School and Habitual Eating Are Associated with Risk for Obesity among Overweight Korean Children: A Prospective Study
}

\author{
Eun Young Lee ${ }^{a} \quad$ Borami Kang $^{\text {a }}$ Yeoree Yang $^{a}$ Hae Kyung Yang ${ }^{a}$ \\ Hun-Sung Kim ${ }^{a}$ b Sun-Young Lim ${ }^{b}$ Jin-Hee Lee ${ }^{b}$ Seong-Su Lee ${ }^{c}$ \\ Byung-Kyu Suhd Kun-Ho Yoon ${ }^{a}$, b
}

${ }^{a}$ Division of Endocrinology and Metabolism, Department of Internal Medicine, Seoul St. Mary's Hospital, College of Medicine, The Catholic University of Korea, Seoul, South Korea; ${ }^{b}$ Institute of Catholic Ubiquitous Health Care, The Catholic University of Korea, Seoul, South Korea; ' Division of Endocrinology and Metabolism, Department of Internal Medicine, Bucheon St. Mary's Hospital, College of Medicine, The Catholic University of Korea, Seoul, South Korea; ${ }^{d}$ Department of Pediatrics, Seoul St. Mary's Hospital, College of Medicine, The Catholic University of Korea, Seoul, South Korea

\section{Keywords}

Childhood · Eating behavior - Obesity · Overweight - Sedentary time

\begin{abstract}
Objective: To investigate behavioral factors that contribute to the development of obesity among overweight children. Methods: Among a community sample of 884 children aged 9-13 years, 833 children completed a baseline and 1-year follow-up examination that included anthropometrics, physical fitness, and behavioral factors. Results: During the follow-up period, BMI for most children with normal weight or obesity did not change. However, among overweight children $(n=100)$, about one-third developed obesity $(n=26)$, while the others were categorized as normal weight $(n=32)$ or overweight $(n=42)$ after 1 year. Characteristics of overweight children at baseline and follow-up were analyzed. Those who developed obesity showed a notable increase in blood pressure as well as in BMI, waist circumference, and body fat over 1 year. At baseline, this group spent more time studying after school compared to overweight children who did not develop obesity, while there were no differences in time spent viewing television or engaging in vigorous physical activity. Eating outside the home, fast food consumption, and habitual eating in the absence of hunger were more common at baseline in those who did versus those who did not develop obesity. After adjusting for age,
\end{abstract}


Lee et al.: Study Time after School and Habitual Eating Are Associated with Risk for Obesity among Overweight Korean Children: A Prospective Study

sex, and BMI, spending more time studying after school and habitual eating without hunger were associated with the development of obesity. Conclusion: Among Korean overweight children, study time after school and habitual eating without hunger were associated with an increased risk for development of obesity.

(C) 2018 The Author(s)

Published by S. Karger GmbH, Freiburg

\section{Introduction}

Childhood obesity is an increasingly important public health issue. The prevalence of obesity among children and adolescents has steadily increased over the last few decades [1]. This phenomenon is not limited to Western countries, but is also observed in the Asian population [2]. In 2013, the prevalence of childhood obesity was greater than $10 \%$ in developing countries and even higher $(>20 \%)$ in developed countries [1]. In addition, the combined prevalence of overweight and obesity among children has increased by $47.1 \%$ from 1980 to 2013 [1].

There are serious health implications associated with childhood obesity, which can contribute to cardiovascular and metabolic abnormalities during early childhood or puberty [3-7]. More than $50 \%$ of children with obesity have at least one cardiometabolic risk factor [4]. Dyslipidemia, abnormal glucose regulation, and increased fasting insulin levels often accompany childhood obesity [4,5], which is also closely associated with future cardiovascular and metabolic diseases. Elevated blood pressure in children with obesity can put them at $30-40 \%$ greater risk for future stroke and ischemic heart disease [5]. Previous studies have demonstrated a relative risk of 1.5-5.1 for cardiometabolic diseases such as diabetes, hypertension, stroke, and ischemic heart disease in children with obesity [6]. Furthermore, childhood obesity is associated with increased premature adult mortality, with a relative risk of 1.4-2.9 compared to children without obesity [6, 7].

For these reasons, earlier management of childhood obesity is critical. Given its increasing prevalence, methods of prevention and intervention in overweight children who are at high risk for obesity are needed. There are few studies evaluating predictors of obesity in overweight children; thus, we investigated behavioral factors that contributed to the development of obesity among overweight children over 1 year.

\section{Material and Methods}

\section{Study Population and Physical Examination}

A total of 884 children aged 9-13 years were recruited from five elementary and middle schools in Chung-Ju city. This cohort is part of an ongoing prospective community-based study that began in 2014. At the first follow-up examination in 2015, 833 children completed the anthropometric measures, physical fitness testing, and questionnaires. Body weight and composition (fat and muscle) were measured using bioimpedance analysis (IOI 353; Jawon Medical, Seoul, South Korea). This analysis was performed in the morning, after an overnight fast, with children wearing light clothing and no accessories. Waist circumference was measured within $0.1 \mathrm{~cm}$ using a plastic tapeline. BMI $\left(\mathrm{kg} / \mathrm{m}^{2}\right)$ was used to define overweight ( $\geq 85$ th percentile), obese ( $\geq 95$ th percentile or $25 \mathrm{~kg} / \mathrm{m}^{2}$ ), and normal weight $(<85$ th percentile). We used the Korean Centers for Disease Control and Prevention (KCDC) standard growth charts as an indicator for age- and sex-specific percentiles for BMI [8]. Height was measured within $0.1 \mathrm{~cm}$ using BIKI 200 (Jawon Medical, Seoul, South Korea). Physical fitness was measured by four domains: cardiopulmonary endurance, flexibility, muscle strength, and agility. Cardiopulmonary endurance was measured by running for $15 \sim 20 \mathrm{~m}$. Flexibility, muscle strength, and agility were evaluated by trunk flection, grip strength, and standing long jump test, respectively. All tests were performed at least twice, and the total of all scores were recorded, based on the standards proposed by the Ministry of Education, Science and Technology of South Korea in 2009 [9]. The study protocol was approved by the Ethics Committee of Seoul St. Mary's Hospital (KIRB-00465-005). 
Lee et al.: Study Time after School and Habitual Eating Are Associated with Risk for Obesity among Overweight Korean Children: A Prospective Study

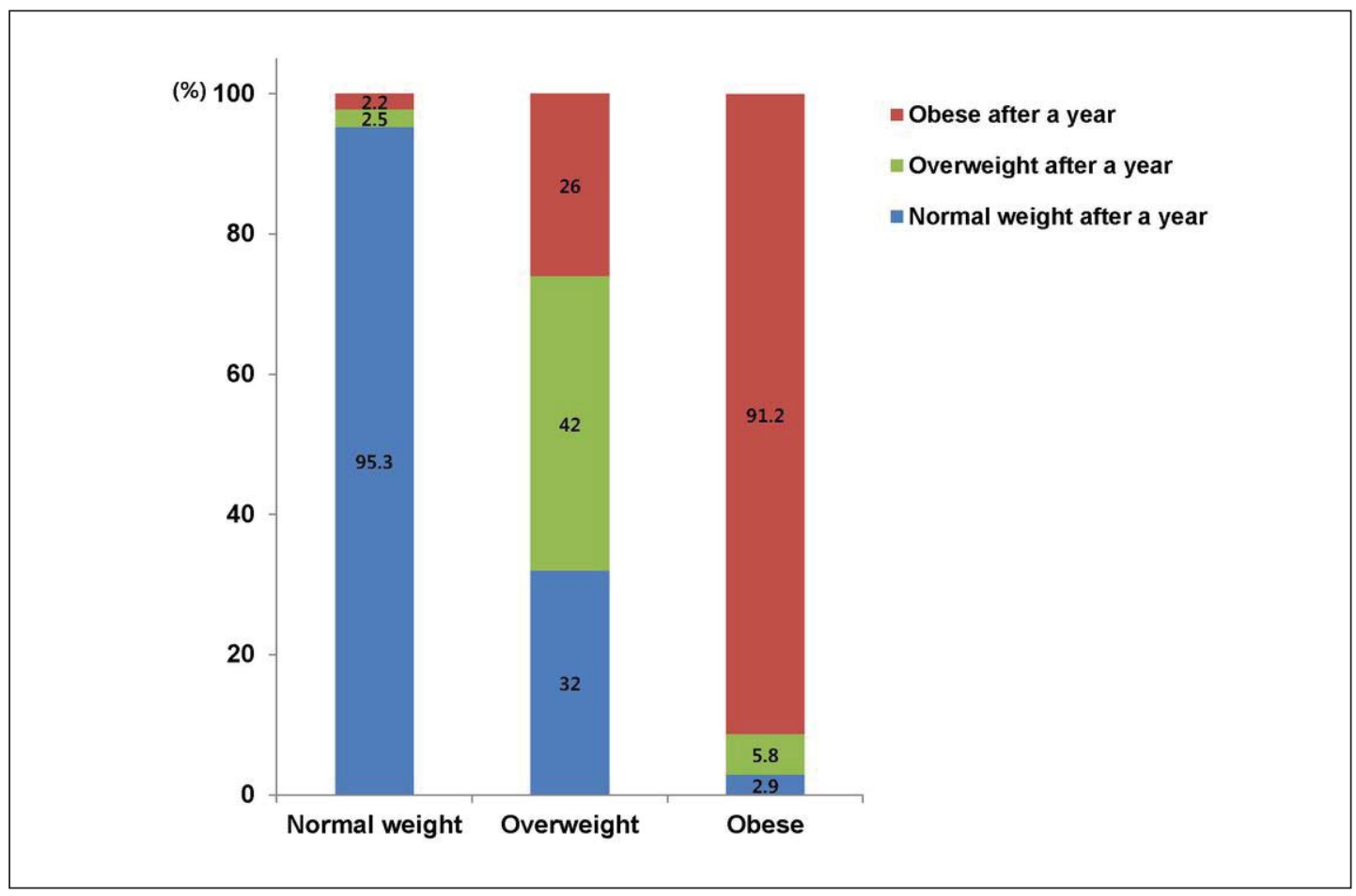

Fig. 1. Changes in BMI categories among 833 children during 1 year of follow-up.

\section{Questionnaire of Behavioral Factors}

Behavioral and emotional characteristics were assessed using self-reported questionnaires that targeted areas such as physical activity, sleep, eating frequency, and eating behavior. The physical activity questionnaire investigated the frequency of vigorous physical activity, type and duration of exercise outside of gym class, amount of TV watching or computer use, and preference for physical activity. To evaluate eating patterns, children were asked how often they ate 12 specific foods, such as fruit, vegetables, milk, soda, bread, candy, or fast food. Eating behavior was evaluated by 16 questions including eating speed, number and regularity of meal times, and frequency of eating outside the home, night snacking, impulsive eating, and eating in the absence of hunger. These questionnaires were modified from the questionnaire suggested by the Youth Health Behavior Survey and the Children and Adolescent Obesity of South Korea [10].

\section{Statistical Analysis}

Data are presented as mean \pm standard deviation (SD) or $\mathrm{n}(\%)$. Analysis of variance (ANOVA) and post hoc analysis were performed to compare groups according to the weight category. Categorical variables were analyzed using the Mantel-Haenszel $\chi^{2}$ or McNemar test. Univariate regression analysis was used to evaluate associations between obesity and behavioral or emotional factors. Multi-nominal logistic regression analysis was performed to control for potential confounders. All statistical analyses were performed using SPSS version 20.0 (IBM Corp., Armonk, NY, USA). A p value of $<0.05$ was considered to be statistically significant.

\section{Results}

\section{Baseline Characteristics of Study Population}

At baseline, $12.1 \%$ (boys $11.3 \%$; girls $14.8 \%$ ) and $16.4 \%$ (boys $17.8 \%$; girls $11.7 \%$ ) of children were overweight and obese, respectively. The prevalence of overweight decreased to $7.8 \%(p=0.029)$ after 1 year of follow-up, while the prevalence of obesity increased to 
Lee et al.: Study Time after School and Habitual Eating Are Associated with Risk for Obesity among Overweight Korean Children: A Prospective Study

Table 1. Baseline characteristics of overweight children by BMI categories after 1 year*

\begin{tabular}{lllll}
\hline & $\begin{array}{l}\text { Normal weight } \\
(\mathrm{n}=32)\end{array}$ & $\begin{array}{l}\text { Overweight } \\
(\mathrm{n}=42)\end{array}$ & $\begin{array}{l}\text { Obese } \\
(\mathrm{n}=26)\end{array}$ & p value $^{\#}$ \\
\hline Age, years & $10.9 \pm 1.6$ & $9.9 \pm 1.2^{\mathrm{a}}$ & $11.0 \pm 1.4^{\mathrm{b}}$ & 0.003 \\
Female sex (\%) & $8(25.0)$ & $16(38.1)$ & $3(11.5)$ & 0.315 \\
SBP, mm Hg & $123.7 \pm 13.5$ & $118.2 \pm 10.6$ & $116.1 \pm 11.6^{\mathrm{a}}$ & 0.039 \\
DBP, mm Hg & $75.3 \pm 10.5$ & $76.0 \pm 8.7$ & $72.5 \pm 10.3$ & 0.335 \\
Height, cm & $152.1 \pm 12.5$ & $143.3 \pm 8.8^{\mathrm{a}}$ & $152.0 \pm 10.7^{\mathrm{b}}$ & $<0.001$ \\
Weight, kg & $53.4 \pm 11.7$ & $46.0 \pm 7.7^{\mathrm{a}}$ & $55.0 \pm 9.5^{\mathrm{b}}$ & $<0.001$ \\
WC, cm & $75.1 \pm 7.5$ & $73.3 \pm 6.6$ & $78.3 \pm 5.4^{\mathrm{b}}$ & 0.011 \\
BMI, kg/m ${ }^{2}$ & $22.7 \pm 1.6$ & $22.2 \pm 1.3$ & $23.6 \pm 1.2^{\mathrm{a}}$ & $<0.001$ \\
BMI percentile & $87.7 \pm 2.6$ & $89.3 \pm 2.4^{\mathrm{a}}$ & $90.1 \pm 2.6^{\mathrm{a}}$ & $<0.001$ \\
Body fat, \% & $22.9 \pm 3.1$ & $22.8 \pm 3.3$ & $23.4 \pm 2.7$ & 0.696 \\
Fat mass, kg & $12.4 \pm 3.3$ & $10.5 \pm 2.6^{\mathrm{a}}$ & $12.9 \pm 2.7^{\mathrm{b}}$ & 0.002 \\
Muscle mass, kg & $38.1 \pm 8.2$ & $32.8 \pm 5.3^{\mathrm{a}}$ & $39.0 \pm 6.8^{\mathrm{b}}$ & $<0.001$ \\
Physical fitness & & & & \\
$\quad$ Cardiopulmonary endurance & $6.8 \pm 3.6$ & $7.5 \pm 3.2$ & $6.6 \pm 2.8$ & 0.516 \\
$\quad$ Flexibility & $8.9 \pm 6.1$ & $7.3 \pm 5.9$ & $8.2 \pm 5.8$ & 0.523 \\
$\quad$ Muscle strength & $8.3 \pm 3.0$ & $7.9 \pm 2.8$ & $9.0 \pm 2.8$ & 0.314 \\
$\quad$ Agility & $7.7 \pm 3.7$ & $7.8 \pm 3.4$ & $7.9 \pm 3.1$ & 0.957 \\
$\quad$ Total score & $36.7 \pm 8.6$ & $35.2 \pm 10.5$ & $35.8 \pm 10.2$ & 0.814 \\
\hline
\end{tabular}

DBP = Diastolic blood pressure; SBP = systolic blood pressure; $\mathrm{WC}=$ waist circumference .

*Data were shown as mean \pm SD or number (\%).

\#P value is for ANOVA analysis among three groups.

andicates a significant difference between obese and normal weight.

${ }^{\mathrm{b}}$ Indicates a significant difference between obese and overweight.

Table 2. Difference in blood pressure and anthropometrics over one year in overweight children according to BMI categories after 1 year*

\begin{tabular}{lllll}
\hline & $\begin{array}{l}\text { Normal weight } \\
(\mathrm{n}=32)\end{array}$ & $\begin{array}{l}\text { Overweight } \\
(\mathrm{n}=46)\end{array}$ & $\begin{array}{l}\text { Obese } \\
(\mathrm{n}=26)\end{array}$ & $\mathrm{p} \mathrm{value}^{\#}$ \\
\hline$\Delta$ SBP, mm Hg & $-6.9 \pm 15.9$ & $0.1 \pm 11.2$ & $3.3 \pm 13.3 \mathrm{a}$ & 0.014 \\
$\Delta$ DBP, mm Hg & $-1.5 \pm 13.1$ & $1.6 \pm 9.6$ & $4.2 \pm 13.7$ & 0.201 \\
$\Delta$ Height, cm & $6.4 \pm 3.1$ & $6.0 \pm 1.6$ & $6.0 \pm 2.1$ & 0.678 \\
$\Delta$ Weight, kg & $1.7 \pm 3.9$ & $5.6 \pm 1.8 \mathrm{a}$ & $9.7 \pm 2.4 \mathrm{a}, \mathrm{b}$ & $<0.001$ \\
$\Delta$ WC, cm & $0.8 \pm 5.0$ & $4.0 \pm 6.1 \mathrm{a}$ & $6.1 \pm 4.3 \mathrm{a}$ & 0.001 \\
$\Delta$ BMI, kg/m ${ }^{2}$ & $-1.1 \pm 1.2$ & $0.8 \pm 0.8 \mathrm{a}$ & $2.1 \pm 0.8 \mathrm{a}, \mathrm{b}$ & $<0.001$ \\
$\Delta$ BMI percentile & $-12.4 \pm 10.4$ & $-0.4 \pm 3.2 \mathrm{a}$ & $3.5 \pm 2.2 \mathrm{a}, \mathrm{b}$ & $<0.001$ \\
$\Delta$ Body fat, \% & $-2.1 \pm 3.2$ & $1.5 \pm 2.0 \mathrm{a}$ & $3.6 \pm 1.9 \mathrm{a}, \mathrm{b}$ & $<0.001$ \\
$\Delta$ Fat mass, kg & $-0.7 \pm 2.2$ & $2.1 \pm 1.2 \mathrm{a}$ & $4.7 \pm 1.7 \mathrm{a}, \mathrm{b}$ & $<0.001$ \\
$\Delta$ Muscle mass, kg & $2.4 \pm 2.3$ & $3.2 \pm 1.3 \mathrm{a}$ & $4.5 \pm 1.4 \mathrm{a}, \mathrm{b}$ & $<0.001$ \\
$\Delta$ Muscle mass $-\Delta$ fat mass, kg & $3.1 \pm 2.5$ & $1.2 \pm 1.8 \mathrm{a}$ & $-0.1 \pm 2.0 \mathrm{a}, \mathrm{b}$ & $<0.001$
\end{tabular}

DBP = Diastolic blood pressure; SBP = systolic blood pressure; $\mathrm{WC}=$ waist circumference; $\Delta=$ values 1 year after minus values at baseline.

*Data are shown as mean \pm SD.

\# $\mathrm{P}$ value is for ANOVA analysis among three groups.

andicates a significant difference between obese and normal weight.

bIndicates a significant difference between obese and overweight. 
$19.7 \%(\mathrm{p}<0.001)$. Obesity significantly increased in boys $(22.0 \%, \mathrm{p}<0.001)$, but not in girls $(11.7 \%, \mathrm{p}=1.000)$ after 1 year. Most children with normal weight $(95.3 \%)$ or obesity $(91.2 \%)$ at baseline remained in the same BMI categories during follow-up (fig. 1). However, among children who were overweight at baseline $(n=100)$, 32 were normal-weight, 42 were overweight, and 26 were obese 1 year later.

We categorized overweight children at baseline into 3 groups according to BMI categories after 1 year of follow-up. Baseline BMI was higher in children whose BMI category changed to obesity, compared to those whose BMI category changed to normal weight (table 1). Although baseline systolic blood pressure (SBP) was low in children whose BMI category changed to obesity after 1 year (table 1), it significantly increased during follow-up, while it decreased in children whose BMI category changed to normal weight (table 2). There was no significant difference in physical fitness levels at baseline according to BMI categories after 1 year.

\section{Anthropometric Changes over 1 Year and Baseline Behavioral Characteristics According} to BMI Categories

During the follow-up period, weight gain was more prominent in children who developed obesity compared to others. Likewise, there was a greater increase in anthropometrics, such as waist circumference, BMI, and body fat percentage in overweight children who developed obesity compared to those who did not (table 3). Although there were no significant differences in vigorous physical activity or TV viewing, children who developed obesity during follow-up spent greater amounts of time studying after school compared to those without obesity ( $\mathrm{p}$ for trend $=0.046$; table 3 ). They also reported worse eating habits, such as fast food or fatty food consumption and eating outside the home, compared to those who did not develop obesity ( $p=0.028$ and $p=0.002$, respectively). Soda intake and breakfast consumption tended to increase in children with obesity, but not significantly $(\mathrm{p}=0.116$ and $\mathrm{p}=0.103$, respectively). Children with obesity were more often noted to eat habitually in the absence of hunger compared to those without obesity $(p=0.002)$, and tended to eat impulsively or under stress, but not significantly $(\mathrm{p}=0.071)$.

\section{Multinominal Regression Analysis for Developing Obesity after 1 Year}

On regression analysis, children with normal weight after 1 year were used as a reference group, and their baseline characteristics were compared to those of children who remained overweight and to those of children who developed obesity after 1 year. As shown in table 4, after adjusting for age and sex, greater time spent in after-school study was significantly associated with development of obesity after 1 year (odds ratio (OR), 6.39 (95\% confidence interval (CI) 1.08-37.72); $\mathrm{p}=0.041)$. This relationship remained significant even after adjusting for BMI (OR, 13.30 (95\% CI, 1.76-100.27); $\mathrm{p}=0.012)$. Habitual eating without hunger also showed an independent association with development of obesity after adjusting for age, sex, and BMI (OR, 13.76 (95\% CI, 1.29-147.14); p = 0.030). Although frequent eating of fast food or fatty food and breakfast were associated with developing obesity after 1 year, these relationships were not significant after adjusting for other confounders.

\section{Discussion}

In the present study, we observed that most children with normal weight or obesity at baseline remained in the same BMI categories during 1 year of follow-up. However, overweight children were more likely to change their BMI category compared to those with normal weight or obesity. About one-third of overweight children developed obesity after 1 
Lee et al:: Study Time after School and Habitual Eating Are Associated with Risk for Obesity among Overweight Korean Children: A Prospective Study

Table 3. Baseline behavioral and emotional characteristics of overweight children by BMI categories after 1 year*

\begin{tabular}{|c|c|c|c|c|}
\hline & $\begin{array}{l}\text { Normal weight } \\
(\mathrm{n}=30)\end{array}$ & $\begin{array}{l}\text { Overweight } \\
(n=40)\end{array}$ & $\begin{array}{l}\text { Obese } \\
(n=23)\end{array}$ & $\mathrm{p}$ value \\
\hline \multicolumn{5}{|l|}{ Lifestyle } \\
\hline \multicolumn{5}{|c|}{ Vigorous physical activity } \\
\hline$<1 \mathrm{~h}$ & $21(70.0)$ & $23(57.5)$ & $12(57.1)$ & \multirow[t]{3}{*}{0.472} \\
\hline $1 \sim 2 \mathrm{~h}$ & $4(13.3)$ & $13(32.5)$ & $5(23.8)$ & \\
\hline$\geq 2 \mathrm{~h}$ & $5(16.7)$ & $4(10.0)$ & $4(19.0)$ & \\
\hline \multicolumn{5}{|c|}{ Exercise out of gym class } \\
\hline No & $9(30.0)$ & $11(27.5)$ & $8(34.8)$ & \multirow[t]{2}{*}{0.740} \\
\hline Yes & $21(70.0)$ & $29(72.5)$ & $15(25.2)$ & \\
\hline \multicolumn{5}{|c|}{ Study after school } \\
\hline$<1 \mathrm{~h}$ & $10(34.5)$ & $9(22.5)$ & $3(13.0)$ & \multirow[t]{3}{*}{0.046} \\
\hline $1 \sim 3 \mathrm{~h}$ & $14(48.3)$ & $21(52.5)$ & $12(52.2)$ & \\
\hline$\geq 3 \mathrm{~h}$ & $5(17.2)$ & $10(25.0)$ & $8(34.8)$ & \\
\hline \multicolumn{5}{|c|}{ TV viewing } \\
\hline$<1 \mathrm{~h}$ & $21(72.4)$ & $19(47.5)$ & $11(47.8)$ & \multirow[t]{3}{*}{0.181} \\
\hline $1 \sim 3 \mathrm{~h}$ & $7(24.1)$ & $15(37.5)$ & $12(52.2)$ & \\
\hline$\geq 3 \mathrm{~h}$ & $1(3.4)$ & $6(15.0)$ & $0(0)$ & \\
\hline \multicolumn{5}{|l|}{ Sleep time } \\
\hline$<7 \mathrm{~h}$ & $2(7.1)$ & $1(2.5)$ & $0(0)$ & \multirow[t]{3}{*}{0.287} \\
\hline $7 \sim 8 \mathrm{~h}$ & $17(60.7)$ & $25(62.5)$ & $11(57.9)$ & \\
\hline$\geq 9 \mathrm{~h}$ & $9(32.1)$ & $14(35.0)$ & $8(42.1)$ & \\
\hline \multicolumn{5}{|c|}{ Food frequency } \\
\hline \multicolumn{5}{|l|}{ Fruit } \\
\hline$\leq 6$ & $20(71.4)$ & $28(73.7)$ & $16(69.6)$ & \multirow[t]{2}{*}{0.900} \\
\hline Daily & $8(28.6)$ & $10(26.3)$ & $7(30.4)$ & \\
\hline \multicolumn{5}{|l|}{ Vegetable } \\
\hline$\leq 2$ & $6(20.7)$ & $6(15.8)$ & $2(9.1)$ & \multirow[t]{3}{*}{0.365} \\
\hline $3 \sim 6$ & $13(44.8)$ & $18(47.4)$ & $11(50.0)$ & \\
\hline Daily & $10(34.5)$ & $14(36.8)$ & $9(40.9)$ & \\
\hline \multicolumn{5}{|l|}{ Soda } \\
\hline$\leq 2$ & $24(82.8)$ & $29(74.4)$ & $16(69.6)$ & \multirow[t]{3}{*}{0.116} \\
\hline $3 \sim 4$ & $5(17.2)$ & $6(15.4)$ & $4(17.4)$ & \\
\hline$\geq 5$ & $0(0)$ & $4(10.3)$ & $3(13.0)$ & \\
\hline \multicolumn{5}{|c|}{ Candy or sweetener } \\
\hline$\leq 2$ & $22(75.9)$ & $27(67.5)$ & $16(69.6)$ & \multirow[t]{3}{*}{0.253} \\
\hline $3 \sim 4$ & $6(20.7)$ & $10(25.0)$ & $3(13.0)$ & \\
\hline$\geq 5$ & $1(3.4)$ & $3(7.5)$ & $4(17.4)$ & \\
\hline \multicolumn{5}{|c|}{ Fast or fatty food } \\
\hline$<1$ & $16(55.2)$ & $13(32.5)$ & $6(26.1)$ & \multirow[t]{2}{*}{0.028} \\
\hline$\geq 1$ & 13 (44.8) & $27(67.5)$ & $17(73.9)$ & \\
\hline
\end{tabular}

Table 3 continued on next page

year while the other two-thirds did not. Greater time spent in after-school study and habitual eating in the absence of hunger were significantly associated with an increased risk of developing obesity among overweight children.

Recently, many studies have highlighted the negative impact of sedentary time on health, independent of physical activity [11-13]. We observed an association between obesity and sedentary time which was measured as time spent in after-school study, while most previous studies have investigated time spent viewing TV, playing video games, or using the computer $[14,15]$. This may have two implications. First, this may reflect a particular social norm in Korea; namely, an excessive passion (especially among parents) for education requiring 
Lee et al.: Study Time after School and Habitual Eating Are Associated with Risk for Obesity among Overweight Korean Children: A Prospective Study

Table 3. Continued

\begin{tabular}{|c|c|c|c|c|}
\hline & $\begin{array}{l}\text { Normal weight } \\
(\mathrm{n}=30)\end{array}$ & $\begin{array}{l}\text { Overweight } \\
(n=40)\end{array}$ & $\begin{array}{l}\text { Obese } \\
(n=23)\end{array}$ & $\mathrm{p}$ value \\
\hline \multicolumn{5}{|c|}{ Eating behavior } \\
\hline \multicolumn{5}{|c|}{ Breakfast } \\
\hline$\leq 2$ & $6(20.7)$ & $7(17.5)$ & $2(8.7)$ & \multirow[t]{3}{*}{0.103} \\
\hline $3 \sim 5$ & $9(31.0)$ & $3(7.5)$ & $5(21.7)$ & \\
\hline$\geq 6$ & $14(48.3)$ & $30(75.0)$ & $16(69.6)$ & \\
\hline \multicolumn{5}{|c|}{ Regular meal } \\
\hline No & $8(27.6)$ & $8(20.5)$ & $5(21.7)$ & \multirow[t]{2}{*}{0.596} \\
\hline Yes & $21(72.4)$ & $31(79.5)$ & $18(78.3)$ & \\
\hline \multicolumn{5}{|c|}{ Eating slowly } \\
\hline No & $10(35.7)$ & $17(42.5)$ & $9(39.1)$ & \multirow[t]{2}{*}{0.780} \\
\hline Yes & $18(64.3)$ & $23(57.5)$ & $14(60.9)$ & \\
\hline \multicolumn{5}{|c|}{ Frequent or night snack } \\
\hline No & $19(65.5)$ & $21(52.5)$ & $18(78.3)$ & \multirow[t]{2}{*}{0.425} \\
\hline Yes & $10(34.5)$ & $19(47.5)$ & $5(21.7)$ & \\
\hline \multicolumn{5}{|c|}{ Eating outside the home } \\
\hline No & $29(100)$ & $33(82.5)$ & $16(69.6)$ & \multirow[t]{2}{*}{0.002} \\
\hline Yes & $0(0)$ & $7(17.5)$ & $7(30.4)$ & \\
\hline \multicolumn{5}{|c|}{ Habitual eating without hunger } \\
\hline No & $28(9.6)$ & $34(85.0)$ & $17(73.9)$ & \multirow[t]{2}{*}{0.020} \\
\hline Yes & $1(3.4)$ & $6(15.0)$ & $6(26.1)$ & \\
\hline \multicolumn{5}{|c|}{ Eating under stress } \\
\hline No & 27 (93.1) & 37 (92.5) & $18(78.3)$ & \multirow[t]{2}{*}{0.104} \\
\hline Yes & $2(6.9)$ & $3(7.5)$ & $5(21.7)$ & \\
\hline \multicolumn{5}{|c|}{ Impulsive eating } \\
\hline No & $28(96.6)$ & $38(95.0)$ & $19(82.6)$ & \multirow[t]{2}{*}{0.071} \\
\hline Yes & $1(3.4)$ & $2(5.0)$ & $4(17.4)$ & \\
\hline
\end{tabular}

*Data are shown as number (\%). Lifestyle is expressed as mean time spent per day. Food and breakfast frequency are expressed as times per week.

children and adolescents to engage in extracurricular study. A previous study reported that after-school institutional study is routine among Korean children and adolescents [16]. Interestingly, we observed that children spending more time studying spent significantly less time watching TV or using the computer (data not shown). This suggests that sedentary time measured by study time after school could be an important factor for evaluating obesity risk, at least in South Korea. Secondly, a more important aspect is that children and adolescents are prone to eat snacks or fast food during extracurricular study time, which could contribute to obesity. Our observation that children with obesity frequently eat fast food and/or drink soda supports this hypothesis. We also found a positive association between study time after school and frequency of fast food or soda consumption (data not shown). Therefore, it may be prudent to encourage children with obesity to reduce snacks, fast food, or soda to lose weight, rather than to decrease study time. Several studies have shown an association between obesity and memory and attention deficit [17-19], both of which might affect study time. However, we could not explore this association because cognitive function scores were not available.

Eating behaviors have been extensively studied in childhood obesity. The number, regularity, and duration of meals are generally suggested as factors in obesity-related eating behaviors [20]. However, we did not observe any differences in these eating behaviors between children who did and those who did not develop obesity. Only habitual eating in the 


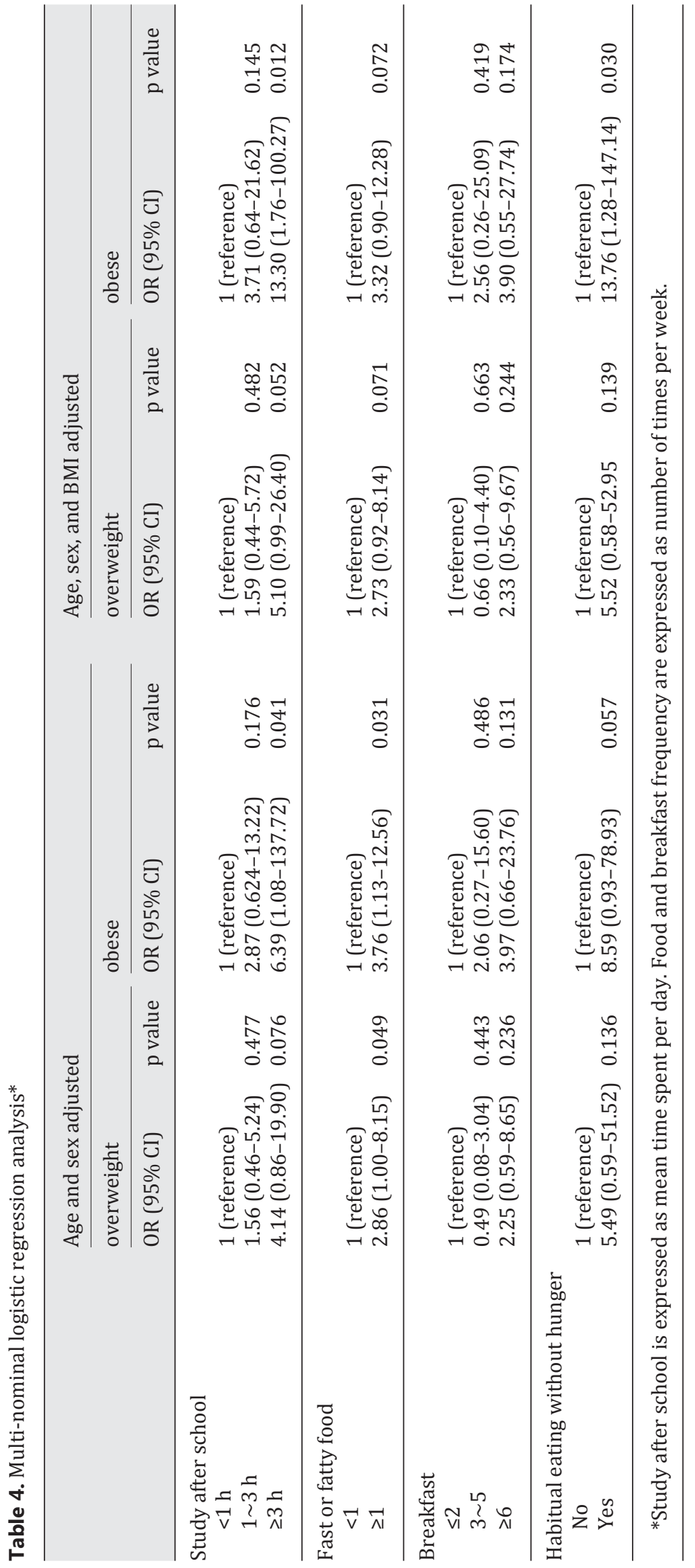


Lee et al.: Study Time after School and Habitual Eating Are Associated with Risk for Obesity among Overweight Korean Children: A Prospective Study

absence of hunger was significantly associated with obesity after adjusting for confounders. Additionally, eating under stress and impulsive eating tended to be greater among children with obesity. This suggests that dietary habits driven by psychological aspects may be more important than the number, regularity, or duration of meals. Consistent with our results, girls eating without hunger were reported to have a 4.6 times greater risk of being overweight [21]. This type of eating behavior in response to presence of food or an emotional state is defined as disinhibited eating, which leads to weight gain and binge eating in adults [22, 23]. To prevent obesity, the regulation of disinhibited eating, particularly during childhood and adolescence, may be necessary. For example, one randomized trial reported that training in food cue responsivity and appetite awareness were effective for reducing eating in the absence of hunger in children [24].

The generalizability of our study may be limited because of the short follow-up period and relatively small number of participants. Lack of laboratory data such as glucose or lipid profile is another limitation. Sedentary time and physical activity data collected from questionnaires are subject to recall bias. However, the prospective study design is a major strength of this study. In addition, we focused on overweight children who are at high risk for obesity, and discovered that their weight was more prone to change compared to children with obesity. Furthermore, we tracked not only BMI changes but also body composition, including fat and muscle mass.

\section{Conclusion}

In the present study, we identified several important behavioral factors that are associated with the development of obesity in overweight Korean children, including increased time spent in after-school study and habitual eating in the absence of hunger. However, these risk factors should be interpreted in the context of potentially different social norms. Further studies in varied social environments are needed to further investigate factors contributing to childhood obesity.

\section{Acknowledgments}

The present study was supported by Social Problem Solving Research Program through the National Research Foundation for Korea (NRF) funded by the Ministry of Science, ICT and Future Planning (2013M3C8A2A02078508). We would like to thank Hee-Sung Ha from the Department of Preventive Medicine, Catholic University of Korea, for her support in statistical analysis. The authors thank Caron Modeas for improving the use of English in the manuscript.

\section{Disclosure Statement}

All authors declare that there are no conflicts of interest.

\section{References}

1 Ng M, Fleming T, Robinson M, Thomson B, Graetz N, Margono C, Mullany EC, Biryukov S, Abbafati C, Abera SF: Global, regional, and national prevalence of overweight and obesity in children and adults during 1980-2013: a systematic analysis for the Global Burden of Disease Study 2013. Lancet 2014;384:766-781.

2 Yoon K-H, Lee J-H, Kim J-W, Cho JH, Choi Y-H, Ko S-H, Zimmet P, Son H-Y: Epidemic obesity and type 2 diabetes in Asia. Lancet 2006;368:1681-1688. 
Lee et al.: Study Time after School and Habitual Eating Are Associated with Risk for Obesity among Overweight Korean Children: A Prospective Study

3 Jekal Y, Yun JE, Park SW, Jee SH, Jeon JY: The relationship between the level of fatness and fitness during adolescence and the risk factors of metabolic disorders in adulthood. Korean Diabetes J 2010;34:126-134.

4 l'Allemand-Jander D: Clinical diagnosis of metabolic and cardiovascular risks in overweight children: early development of chronic diseases in the obese child. Int J Obes 2010;34(suppl 2):S32-S36.

5 Friedemann C, Heneghan C, Mahtani K, Thompson M, Perera R, Ward AM: Cardiovascular disease risk in healthy children and its association with body mass index: systematic review and meta-analysis. 2012; 345:e4759.

6 Reilly JJ, Kelly J: Long-term impact of overweight and obesity in childhood and adolescence on morbidity and premature mortality in adulthood: systematic review. Int J Obes 2011;35:891-898.

7 Franks PW, Hanson RL, Knowler WC, Sievers ML, Bennett PH, Looker HC: Childhood obesity, other cardiovascular risk factors, and premature death. N Engl J Med 2010;362:485-493.

8 Moon JS, Lee SY, Nam CM, Choi J-M, Choe B-K, Seo J-W, Oh K, Jang M-J, Hwang S-S, Yoo MH: 2007 Korean National Growth Charts: review of developmental process and an outlook. Korean JPediatr 2008;51:1-25.

9 Ministry of Education, Science and Technology of South Korea: The Pilot School Management Report of Physical Activity Promotion System. 2009.

10 The Obesity Committee for Children and Adolescents: Childhood and Adolescents Obesity. Seoul, Korean Society for the Study of Obesity, 2012.

11 Biswas A, Oh PI, Faulkner GE, Bajaj RR, Silver MA, Mitchell MS, Alter DA: Sedentary time and its association with risk for disease incidence, mortality, and hospitalization in adults: a systematic review and meta-analysis. Ann Intern Med 2015;162:123-132.

12 Katzmarzyk PT, Church TS, Craig CL, Bouchard C: Sitting time and mortality from all causes, cardiovascular disease, and cancer. Med Sci Sports Exerc 2009;41:998-1005.

13 Owen N, Bauman A, Brown W: Too much sitting: a novel and important predictor of chronic disease risk? $\mathrm{Br}$ J Sports Med 2009;43:81-83.

14 Arluk S, Branch JD, Swain D, Dowling E: Childhood obesity's relationship to time spent in sedentary behavior. Mil Med 2003;168:583-586.

15 Vicente-Rodríguez G, Rey-López JP, Martín-Matillas M, Moreno LA, Wärnberg J, Redondo C, Tercedor P, Delgado M, Marcos A, Castillo M: Television watching, videogames, and excess of body fat in Spanish adolescents: the AVENA study. Nutrition 2008;24:654-662.

16 Kim DM, Ahn CW, Nam SY: Prevalence of obesity in Korea. Obes Rev 2005;6:117-121.

17 Smith E, Hay P, Campbell L, Trollor JN: A review of the association between obesity and cognitive function across the lifespan: implications for novel approaches to prevention and treatment. Obes Rev 2011;12:740755.

18 Li Y, Dai Q, Jackson J, Zhang J: Overweight is associated with decreased cognitive functioning among schoolage children and adolescents. Obesity (Silver Spring) 2008;16:1809-1815.

19 Miller J, Couch J, Schwenk K, Long M, Towler S, Theriaque D, He G, Liu Y, Driscoll D, Leonard C: Early childhood obesity is associated with compromised cerebellar development. Dev Neuropsychol 2009;34:272-283.

20 Rennie KL, Johnson L, Jebb SA: Behavioural determinants of obesity. Best Pract Res Clin Endocrinol Metab 2005;19:343-358.

21 Fisher J, Birch L: Eating in the absence of hunger and overweight in girls from 5 to 7 y of age. Am J Clin Nutr 2002;76:226-231.

22 Williamson DA, Lawson OJ, Brooks ER, Wozniak PJ, Ryan DH, Bray GA, Duchmann EG: Association of body mass with dietary restraint and disinhibition. Appetite 1995;25:31-41.

23 Howard CE, Porzelius LK: The role of dieting in binge eating disorder: etiology and treatment implications. Clin Psychol Rev 1999;19:25-44.

24 Boutelle K, Zucker N, Peterson C, Rydell S, Cafri G, Harnack L: Two novel treatments to reduce overeating in overweight children: a randomized controlled trial. J Consult Clin Psychol 2011;79:759-771. 